\title{
Discovering the mysteries of the Santa Maria di Collemaggio Church (L'Aquila, Italy) by non-destructive testing techniques
}

\author{
by S. Sfarra*, A. Bendada**, C. Ibarra-Castanedo**, D. Ambrosini ${ }^{*}$, D. Paoletti* and X. Maldague**
}

*Las.E.R. Laboratory, Department of Mechanical, Management and Energy Engineering (DIMEG), University of L'Aquila, I-67100, Roio Poggio - L'Aquila (AQ), Italy, \{Stefano.Sfarra, Dario.Ambrosini, Domenica.Paoletti\}@univaq.it

${ }^{* *}$ Computer Vision and System Laboratory, Department of Electrical and Computer Engineering, Laval University, 1065, av. de la Médecine, Quebec City, Canada, G1V 0A6, \{Bendada, IbarraC, MaldagX\}@gel.ulaval.ca

\begin{abstract}
In this study an ancient fresco (Incoronazione dell'Assunta, $15^{\text {th }}$ century) in the Santa Maria di Collemaggio Church (L'Aquila, Italy) containing real damage due to the earthquake of April 2009, which seriously damaged the structure, was inspected by active InfraRed Thermography (IRT) and Near-InfraRed (NIR) Reflectography. On the other hand, the fresco's condition prior to the earthquake was analyzed by Electronic Speckle Pattern Interferometry (ESPI) and Digital Speckle Correlation (DSC). Thermographic inspection data was processed using Principal Component Thermography (PCT) and Pulsed Phase Thermography (PPT), in order to improve the signature of the defects and to reduce the impact of non-uniform heating and emissivity variations due to the painting's pigments. This work also shows that the integration of the non-destructive techniques mentioned above, constitutes an interesting alternative for the in situ inspection of frescoes without impairing their integrity. On the sidelines of the discussion are also reported further analysis by IRT and Ground Penetrating Radar (GPR), which helped to fill gaps in the construction history of the original Church.
\end{abstract}

\section{Introduction}

In the last decade, a heightened interest in cultural heritage has emerged [1, 2]. Today, artwork is considered a personal and cultural patrimony, and great efforts are undertaken to ensure its preservation. In order to maintain the state of a particular piece of art, it is necessary to continuously evaluate its condition, particularly as it ages. This, however, is not always a simple task. There are several complex problems common to the conservation and restoration of artworks [3]. The principal goal is preservation of damage due to external agents such as humidity, pollutants, temperature, mechanical vibrations, etc. Furthermore, it is necessary to schedule preventive maintenance procedures to curtail the aging process. Hence, various diagnostic methods are needed to effectively preserve art treasures. To achieve this, existing technologies that have been developed for application in engineering and in physical sciences can be adapted for use in artwork conservation. In fact, the main feature of these methods is their capability of investigating a site or a structure non-invasively, i.e., without digging, boring or altering its original composition or shape [4-9]. Detailed knowledge of the internal masonry structure of historical monuments is key to their restoration. In general, such structure is composed of different types of stones, bricks, with wooden or iron elements inserted into walls and cavities as ties, etc. $[10,11]$. The recognition of detachments and cracks is crucial to verify the stability of buildings. As is obvious, preference should be given to non-destructive testing techniques while destructive ones (boring and digging) should be minimised, especially when the buildings involved are ancient or highly deteriorated, as in our case after an earthquake. In particular, the data comparison between non-destructive techniques applied before and after a restoration, as well as in the verification of a restoration and after a mechanical shock, provides useful information about both the quality and the technology to be applied in the future [12]. In our case, a difficult task has been the use of non-destructive testing techniques applied on Santa Maria di Collemaggio Church restored several times, in order to understand the change during the time of the original fabric. Bearing in mind this assumption, optical techniques and infrared vision were used on an ancient fresco (Incoronazione dell'Assunta). By the integrated results obtained, we have verified that: 1) the defects treated with the restoration prior to the earthquake of 2009 have arisen once again after it. The comparison and integration between thermographic and interferometric results, allowed us to understand their position and nature, 2) the presence of some signs like gothic letters beneath the painting surface discovered by PCT technique, and 3) some traces of restoration detected by NIR technique [13, 14]. Finally, IRT and GPR were also applied on the fabric. The first, as passive approach in a part of the main facade, in order to identify a presumable buried structure built as reinforcing following the 1915's earthquake, and the second, applied on a part of the Church floor, in order to confirm the presence of a pre-existing shrine.

\section{Historical and architectural outline of the Santa Maria di Collemaggio Church}

Santa Maria di Collemaggio Church is a monumental example of Romanesque-Gothic architecture in Abruzzo (Italy). According to tradition, the place to build the structure was given (1287) to the hermit Pietro da Morrone, who later became Pope (1294) under the name of Celestino $V$ and with the technical and financial aid of the Templar. 
The Church has a nave and two side aisles that are delimited by two external walls. Following the 1997's earthquake Santa Maria di Collemaggio underwent some light repair work, thus moderately strengthened to improve its transversal behaviour. A light steel truss structural system was mounted at roof level to improve the link between the walls; furthermore the walls were injected with cement mortar to enhance the mechanical properties of the masonry.

The facade, approximately rectangular in shape, has a thickness varying from $0.70 \mathrm{~m}$, at the top, up to $1.20 \mathrm{~m}$ near its foundation. It is not as regular as it may seem at first glance. In the front there are three fields separated by vertical parastas. The right field, adjacent to the octagonal squat tower, is wider than the other two.

Its arrangement is not well defined. Basically, at least three leaves of different materials constitutes the wall (Fig. 1a). The actual facade is the result of at least two major structural interventions.

The first performed after the 1915's earthquake, which strongly damaged the upper left corner (Fig. 1b), consisted in a reinforced concrete grid and a leaf of brick masonry at the rear of the facade to improve its resistance out of plane. In order to confirm this, Figure 1c shows the thermographic results as passive approach and the superimpositions with the visible images. Furthermore, this reinforcement was stiffened by means of four vertical brick corbels laying on longitudinal walls. The second performed in 1972: the Baroque superstructure was removed from the main and side aisles, and the ancient octagonal columns and the pointed arches were brought to light [15].
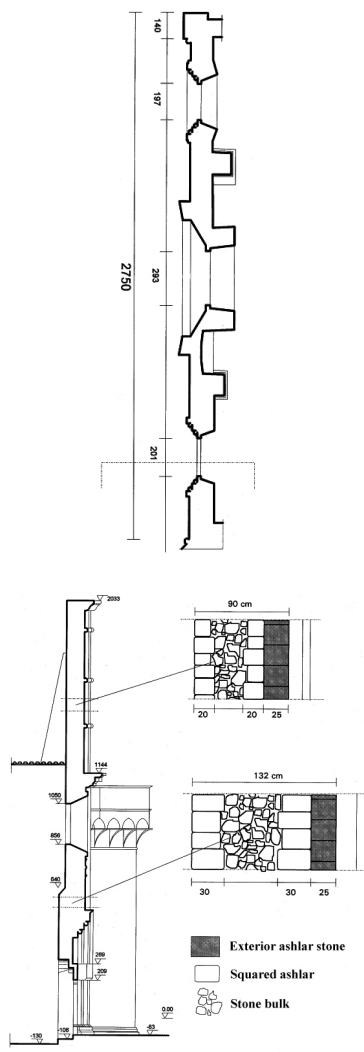

(a)
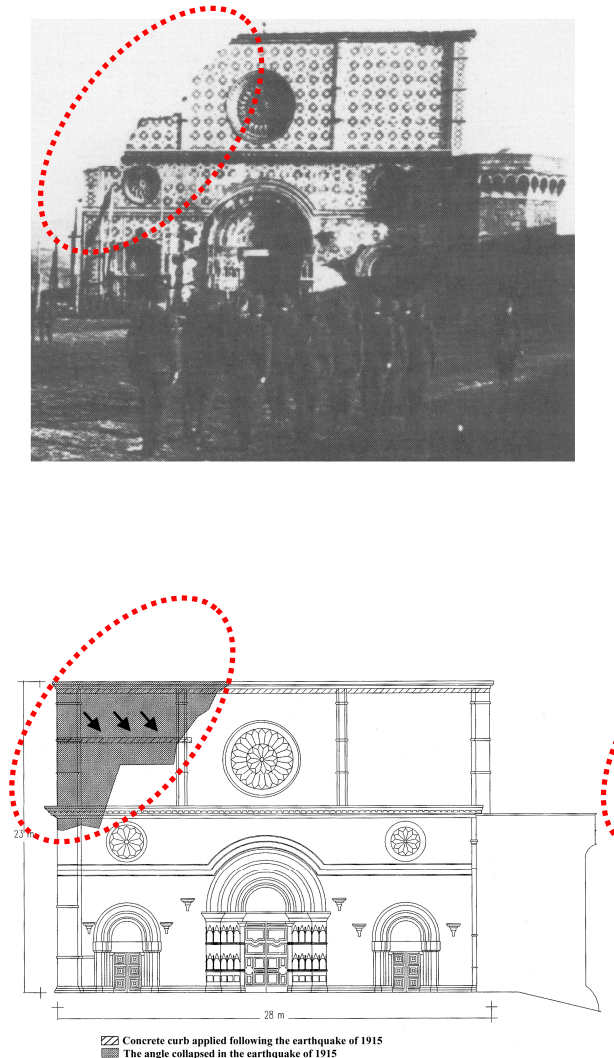

(b)

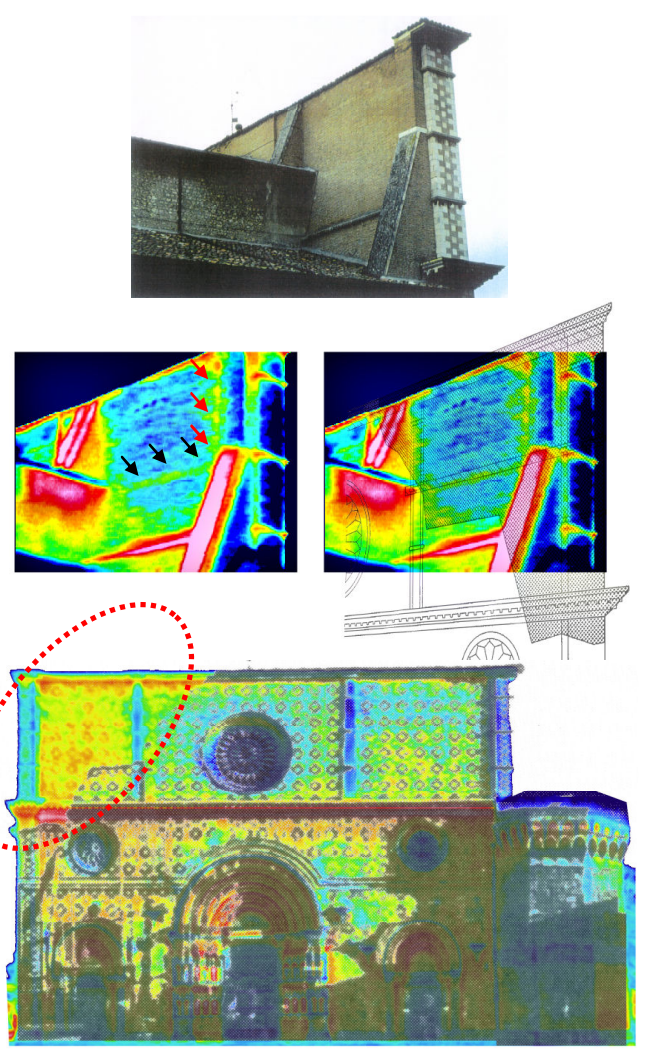

(c)

Fig. 1. (a) plan and section of the main facade, (b) picture and sketch of the main facade after the 1915's earthquake with the structural reinforcements adopted (black arrows), (c) thermograms and image fusions: note the known buried structure detected from the rear side of the facade by IRT (black arrows), and unknown (red arrows) as well as the different "thermal imprint" of the reconstructed part of the facade (red dashed oval).

The facade, where a number of images or carved symbols are depicted on some points of the columns, as well as ornaments positioned in some places on the walls, is decorated with geometric designs in red and white stone.

On right nave wall there are some niches with important examples of frescoes: Madonna con le Sante Apollonia e Agnese fresco, Crocifissione con San Giovanni e San Giuliano fresco, Incoronazione dell'Assunta fresco. The later fresco (Fig. 2) was attributed to the school of the Maestro di San Silvestro (15 ${ }^{\text {th }}$ century) or to the Venetian school of lacobello dal Fiore (around 1430) [16], but our study complements this deduction.

\section{Non-Destructive Testing (NDT) techniques applied}

Relatively to the fresco's study, different non-destructive testing techniques were used in order to confirm the detection of the various defects identified. Below is a list of techniques used with a brief description of their methodology. Interested readers in deepen the concepts, can refer to the cited papers. 
Raking light: is a technique in which a painting is illuminated from one side only, at an oblique angle in relation to its surface. Raking light is used to reveal a painting's surface texture. Raised painted surfaces facing the light are illuminated, while those facing away create shadows. The increased appearance of paint texture can easily be seen, photographed or recorded digitally [17]. Conservators use raking light to judge aspects of the condition of a painting. This technique was very useful to clarify that the signs identified by PCT are not superficial but sub-superficial and in order to understand the defect's nature detected by the same technique.

Electronic Speckle Pattern Interferometry (ESPI): also called Video holography, was developed in the early 1970s as a method of producing interferometric data using video systems instead of holographic materials [18]. The experimental setup to perform ESPI diagnosis resembles holography, with the TV target replacing the glass plate as the recording medium. The reconstruction process is performed electronically with the computer. In practice, the intensity distribution in the detector plane is stored with the object in its reference state. The object is then deformed and a second frame is stored. The two frames are then subtracted electronically to give a resultant intensity distribution. If the speckle patterns from the first and subsequent frames are subtracted and the difference is squared, correlation live fringes are displayed on the TV monitor. By using narrow band filters, centred at the laser wavelength, ESPI systems can also operate in daylight conditions. The resulting fringes are similar in appearance to conventional holographic fringes but with a lower image quality, due to a much more evident speckle noise. For this reason, ESPI fringes are usually digitally treated for noise removal and contrast enhancement. Furthermore, due to the subtractive nature of the reconstruction process, many visible details of the artwork are lost and the precise location of the defect on the artwork can be difficult. This drawback can be alleviated by recording a visual image of the object using the same TV camera of the ESPI system and by superposing on the fringes the edge map of the object [19]. An advantage of ESPI is the possibility to follow the displacement visually on the monitor and to save a suitable record at any time. Finally, ESPI images can be digitally processed to extract a 3D map of the defect. It is then clear that, from an operational point of view, ESPI is faster and simpler to use than conventional holography. ESPI has proved to be a very attractive tool, especially for in situ investigation on frescoes, wooden panels and museum objects $[20,21,22,23,24,25,26]$ as well as on different artworks such as mosaics [27], canvas [28], and terracotta warriors [29]. ESPI can also be used to monitor the artwork conditions over time as well as the effect of sunshine on frescoes [30].

Speckle decorrelation: we can roughly define the correlation between two speckle patterns as the capability to give fringes. Local correlation of laser speckles consists in the evaluation of a local parameter that estimates the decorrelation of speckles after any modification of the test object. Close correspondence exists between the object surface structure and the speckles in the image plane. For this reason, speckle correlation can characterize any physical or chemical mechanism that involves a surface alteration of the order of laser wavelength. To obtain the correlation pattern corresponding to the deformation field, two images are acquired and stored before and after the deformation. Then, a digital subtraction between these two images is performed. If the two images are perfectly correlated, they will cancel completely when subtracted; if there is some decorrelation, the subtraction will not be complete. Therefore, where non-correlation occurs, bright areas are visible, indicating the presence of defects. The technique can provide information about defects on wooden paintings, frescoes and mosaics [24], [31, 32]. It has less sensitivity and image quality than ESPI but it is comparatively cheaper and simpler.

Coin tap test: or screwdriver handle test is a venerable means for manually verifying the integrity of objects and structures, particularly sheet-like and layered materials that are subject to cracking and delaminations. It requires an operator to tap with a small hammer (or a screwdriver handle or some other light-weight object, like a coin) each point of the structure to be inspected, meanwhile feeling the rebound of the hammer and listening to the resulting sound radiated by the impact. Healthy examples typically reverberate cleanly (they sound "live"), whereas damaged examples yield a sound that is dull ("dead"). The operator can discriminate defective examples from good ones by discerning the differences [33].

Near-Infrared Reflectography (NIR): NIR essentially utilizes the radiation of electromagnetic spectrum immediately after the visible region - between 0.7 and $1.1 \mu \mathrm{m}$. Due to the lower attenuation, these waves penetrate deeper into materials than electromagnetic waves of the visible band, and can aid in deciphering the features hidden under opaque layers of material. It was demonstrated [34] that most paints used for art purposes become more transparent when observed in longer wavelengths. In particular, underdrawing visibility is a function of the transparency of the paint layers to NIR radiation and of the underdrawing contrast: IR absorption is high when carbon is present in the drawing (charcoal, graphite, carbonaceous pencils and inks), otherwise iron-gallium-based inks are transparent in the NIR spectrum, hence underdrawing painted with this material would not be detected, even if the paint layer is transparent. Reflectivity is high when the preparation is chalk-and-gypsum based. The techniques, instruments and numerous schemes for this method are well described in literature [35, 36, 37].

Active Infrared Thermography (IRT): is a well-know non-destructive testing and evaluation (NDT\&E) technique, and also the most important used in this work. The basic principle, experimental configuration and advancements are well documented in the literature [38, 39, 40, 41]. In this study, the specimen surface is stimulated with a square heat pulse, while the heating up and the cooling down processes are recorded with an infrared camera for several minutes. The acquired data is then processed to improve defect contrast and signal-to-noise ratio. Several processing techniques exist, from a basic cold image subtraction to more advance techniques such as principle components or higher order statistics. The more relevant to the present study are: pulsed phase thermography (PPT) $[42,43]$ which transform data from the time domain to the frequency domain in order to obtain the phase delay images or phasegrams that have an improved defect contrast; principal component thermography (PCT) [44], which reorganizes into new components that take into account the main spatiotemporal variances of the sequence. 


\section{Nature and decay of wall paintings}

As was pointed out $[45,46]$, the complexity of wall paintings conservation is due to a number of special factors: the physical and aesthetic connection of frescoes with the architecture; their non-homogeneous, multilayer constitution; the fact that "artistic content" of wall paintings constitutes an extremely thin layer, which is also interface between environment and support.

Paintings on wall can be considered as a layered structure with a support. The mural support is coated with plasters, which serve as a base for the painting. These layers are less thick and more fragile than the support. Expansion and contraction of the support due to daily fluctuations of ambient parameters can produce large strains and eventually cracks in the layers, as they become less flexible with age.

Furthermore, abrupt changes of temperature and humidity, traffic induced vibrations, and heat exposure may also cause unpredictable stress distributions in the support with consequent damage of the painted surface. Structural stability of the walls must be carefully considered [45].

\section{Experimental results}

The fresco studied is shown in Figure $2 b_{2}$, which also includes the defects map identified with the various nondestructive testing techniques described above.

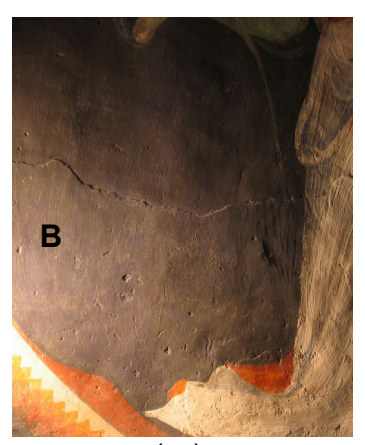

$\left(a_{1}\right)$

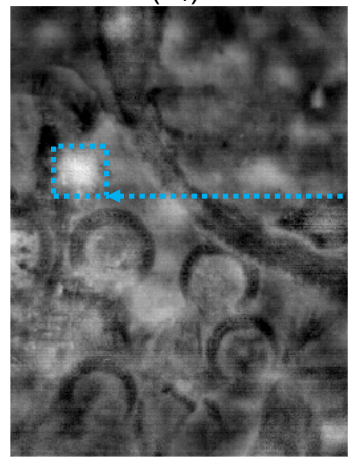

$\left(a_{3}\right)$

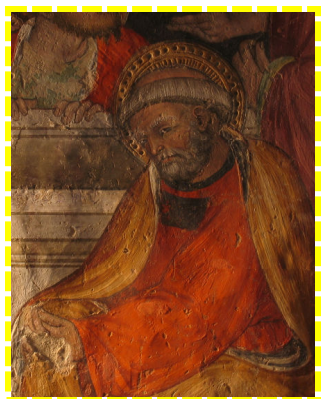

$\left(a_{5}\right)$

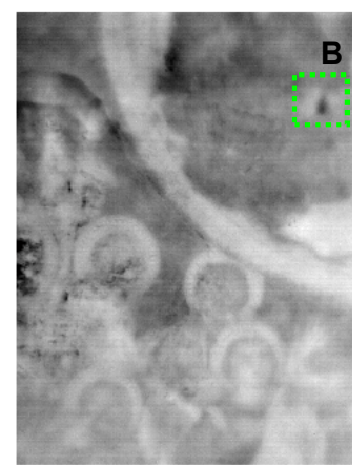

$\left(a_{2}\right)$

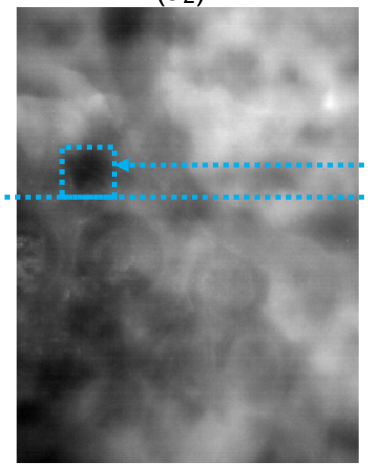

$\left(a_{4}\right), \cdots \cdots$

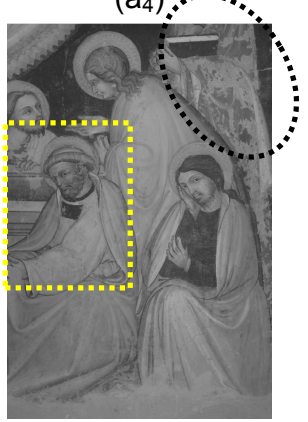

$\left(a_{6}\right)$

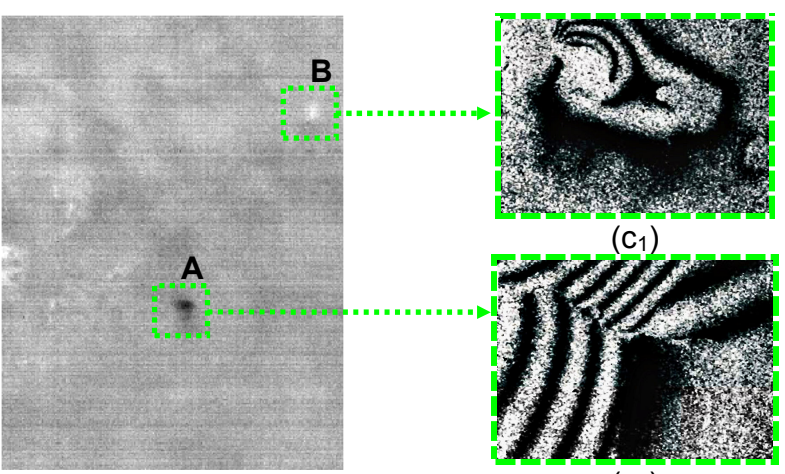

$\left(c_{2}\right)$

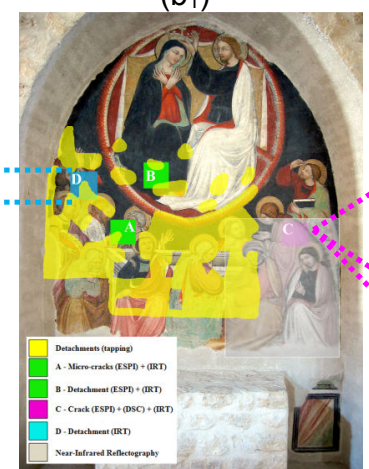

$\left(b_{2}\right) \cdots \cdots$

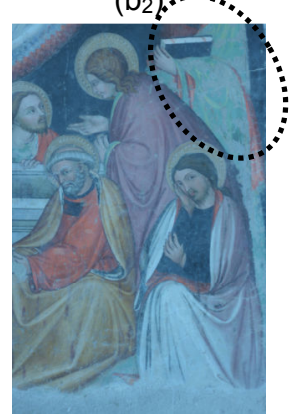

$\left(b_{3}\right)$

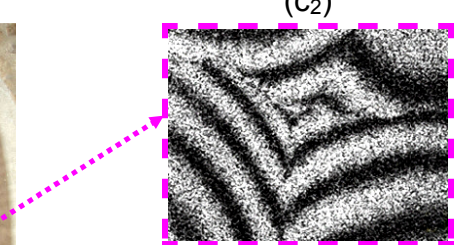

$\left(\mathrm{c}_{3}\right)$

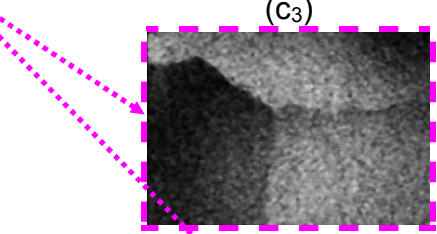

$\because\left(\mathrm{C}_{4}\right)$

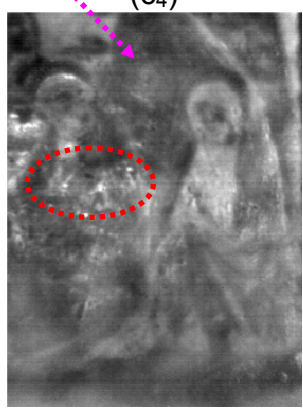

$\left(\mathrm{C}_{5}\right)$

Fig. 2. $\left(a_{1}\right)$ raking light result of the defect $B,\left(a_{2}\right)$ PCT-EOF2, $\left(a_{3}\right)$ phasegram $f=0.002 \mathrm{~Hz},\left(a_{4}\right) P C T-E O F 1,\left(a_{5}\right)$ raking light result of the sub-superficial signs, $\left(a_{6}\right)$ NIR result, $\left(b_{1}\right)$ PCT-EOF7 (first sequence), $\left(b_{2}\right)$ "Incoronazione dell'Assunta" fresco and defects map, $\left(b_{3}\right)$ visible image, $\left(c_{1}\right),\left(c_{2}\right),\left(c_{3}\right)$ ESPI results of the defects $A, B, C$, (c4) Speckle decorrelation result, (c5) PCT-EOF7 (second sequence) 
During a campaign conducted before the earthquake's 2009 [16], the main elements were detected by portable XRF (Assing Lithos 3000) and the hue of the colours by a portable spectrometer (XRITE SP68). The author palette is typical of common and simple pigments: for the whites, bianco S. Giovanni (lime white), for the reds and oranges Mars red, red ochres and Morellone, for the green, terra verde and copper carbonate (malachite).

The absence of light blue colours (azurite) and a large use of green allow to suppose that the azurite has turned into malachite. The yellow are realised with yellow ochres and Mars yellow, blue with lazurite, pink and violet mixing red ochres of various tonalities and bianco S. Giovanni. The carbon was used for the black. The use of gold leaf was not detected. The colours, very dense, were applied, in some case, one over another one.

The painting decay, allows to see under a colour a different hue. This is somehow similar to the NIR inspection shown in Figs. $2 \mathrm{a}_{6}$ and 3b. A CMOS camera (Canon 40DH $22.2 \times 14.8 \mathrm{~mm}-10$ megapixel 0.38-1.1 $\mu \mathrm{m}$ ), with a visible cut-off filter to limit the spectrum to 0.7 to $1.1 \mu \mathrm{m}$ was used. The radiation source, consisted of 1 halogen lamp (STAR Progetti $-2 \mathrm{KW} I \mathrm{R})$, which provide a wide spectrum radiation (including the NIR band).

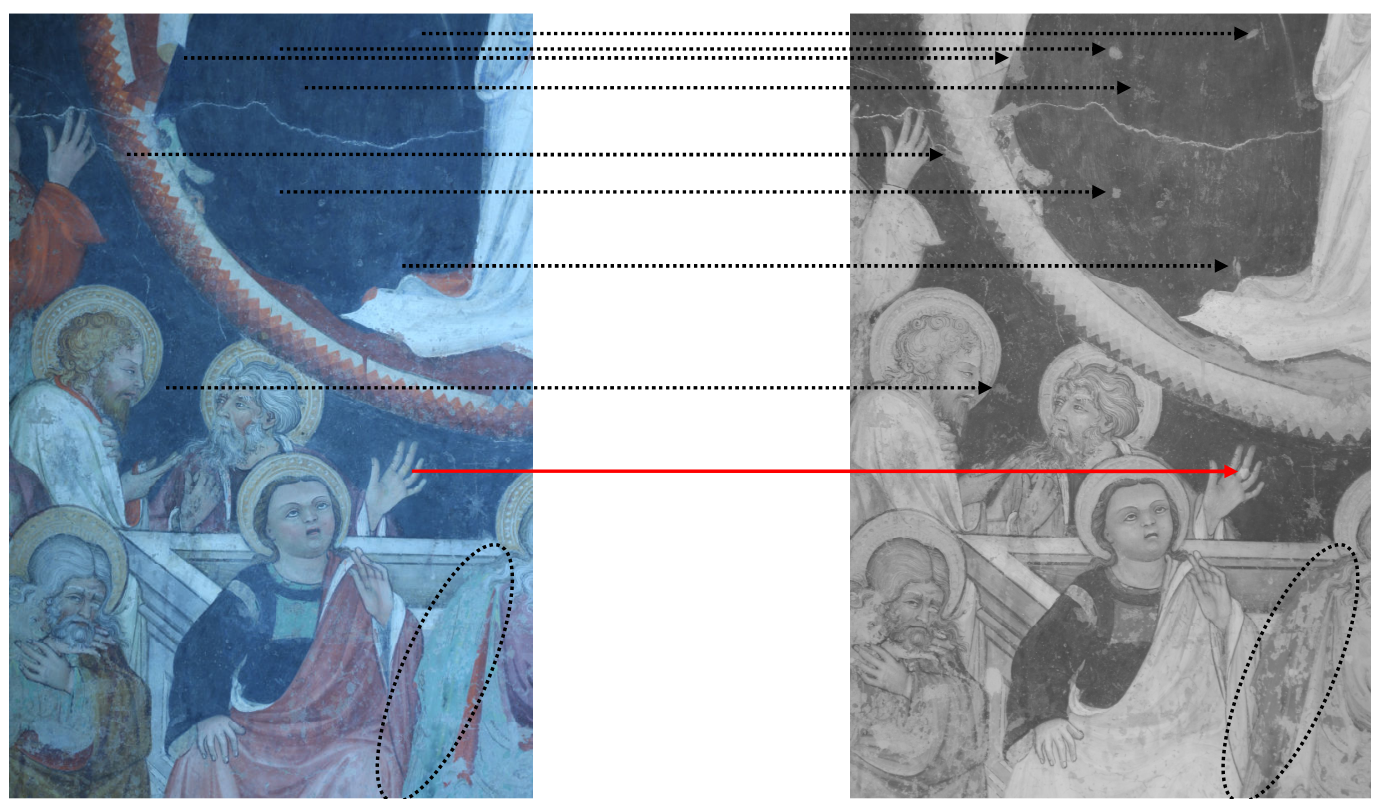

(a) (b)

Fig. 3. (a) visible image, (b) NIR result

Very interesting to note, several paint repairs highlighted with dotted black arrows, the large preservation works that have been made on both mantles of personages highlighted with a black dashed oval in Figs. $2 a_{6}, 3 b$, and an intriguing retouch done on the middle finger of the left hand of the character depicted in Figure 3a, marked with a red solid line. Furthermore, a surprising detection of three signs beneath the orange and ocher mantle of the character shown in Fig. $2 b_{3}$, was obtained by PCT (Figs. $2 \mathrm{c}_{5}, 4 \mathrm{a}$ ) highlighted by a red dashed oval. The same signs are engraved on a stone preserved in the Church and are included in Fig. $4 \mathrm{~b}$ for comparison.

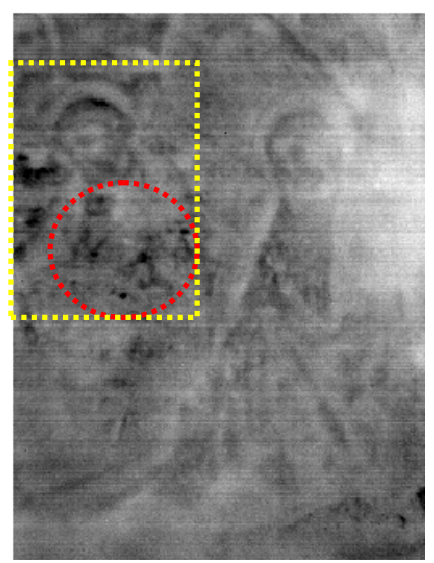

(a)

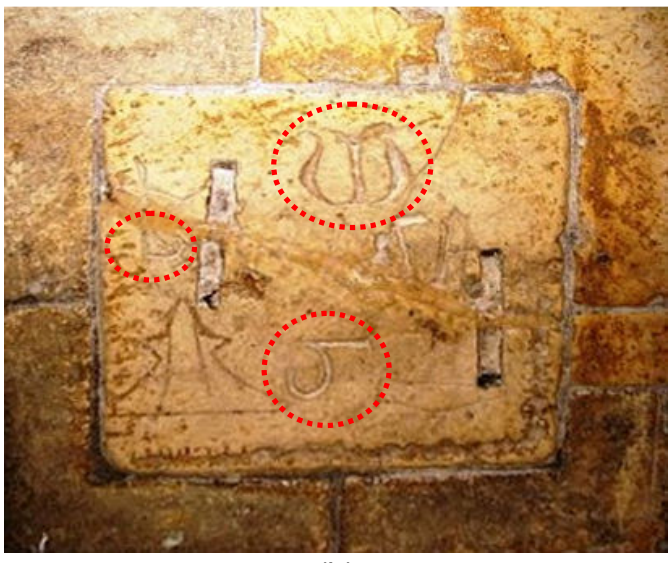

(b)

Fig. 4. (a) PCT-EOF5, (b) stone preserved in the Santa Maria di Collemaggio Church 
At this point, a first possibility that could provide an explanation, is that these graffiti are to be attributed to different periods, and that they are the signs of the builders who worked during the Church's construction. Fig. $5 \mathrm{c}$, obtained by method of Otsu, explains the nature of the signs detected by PCT as graffiti [47]. In fact, these signs resemble gothic letters, and appear to be sub-superficial since they were not identified by neither the raking light result reported in Figure $2 \mathrm{a}_{5}$, nor the NIR inspection image in Fig. $2 \mathrm{a}_{6}$.

If the attention is focused inside the yellow dashed rectangle, the comparison between Fig. $2 \mathrm{a}_{5}$ or Fig. $2 \mathrm{a}_{6}$, Fig. $4 a$ or Fig. $2 c_{5}$, and Fig. $2 b_{3}$, can help the reader to appreciate this result.

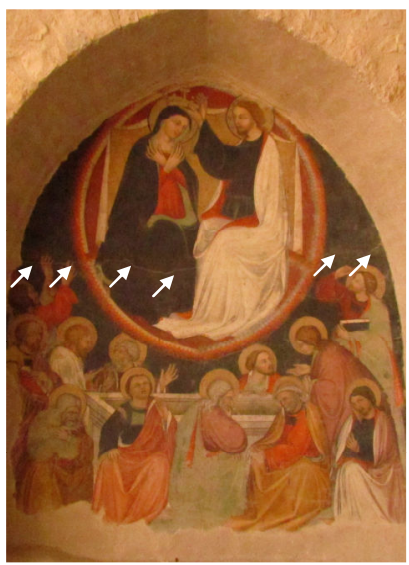

(a)

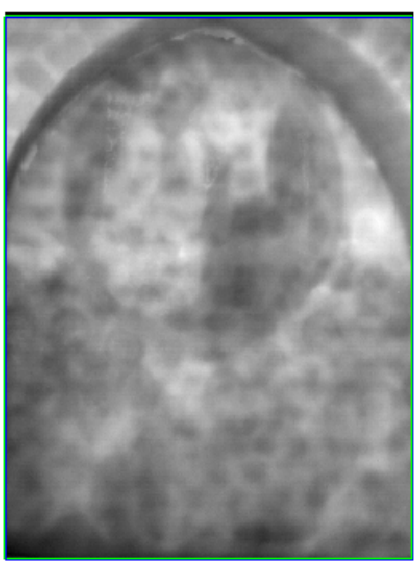

(b)
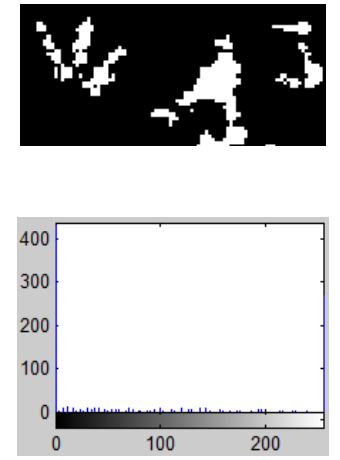

(c)

Fig. 5. (a) visible image, (b) PCT-EOF1 result (third sequence), (c) Threshold text by method of Otsu and histogram of the original image

Furthermore, observing the fresco, it is possible to note a superficial and horizontal crack that separates it in two parts as indicated with the white arrows in Fig. 5a. As said above, the stability of the wall is critical to the painting deformations induced by external factors $[48,49]$. The presence of this crack can be explained, observing and comparing the visible image and the PCT-EOF1 result (third sequence) shown in Figure $5 \mathrm{~b}$. Readers can see as the stones texture which constitute the wall, is aligned vertically above the crack, and transversely below. This lack of structural homogeneity, could have produced the superficial crack during the 2009 earthquake's or before. Taking that into consideration, in addition to the fact that the paint is very dense and superimposed in several layers, and in percentage terms the detachments detected by tapping are mainly distributed below the crack (Fig. $\left.2 \mathrm{~b}_{2}\right)$, a second possibility is that the Incoronazione dell'Assunta fresco was painted above another fresco (previously produced), and it ended up with this crack. This would explain the nature of the three gothic signs identified, namely the artist's signature of the original fresco, which were not detected by NIR technique because of the paint's thickness and/or composition. Moreover, the niches where are located the frescoes are of different shapes, placed at an irregular distance and completely unrelated to the rhythm of the bays [50]. This assumption is also connected to another thermal anomaly relative to a niche of the same Church; the thermographic results as passive approach are reported in Figure 6.
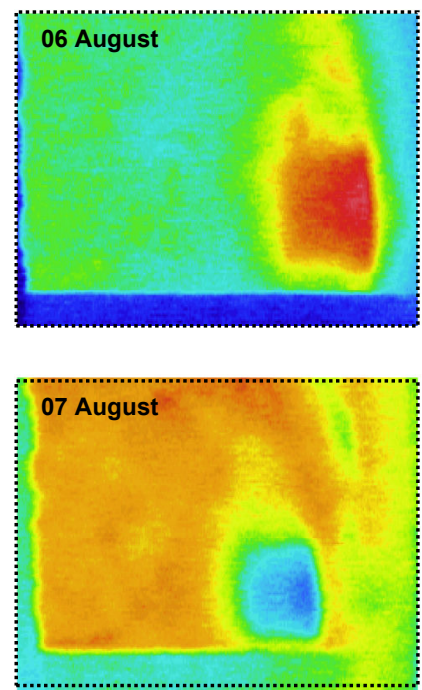

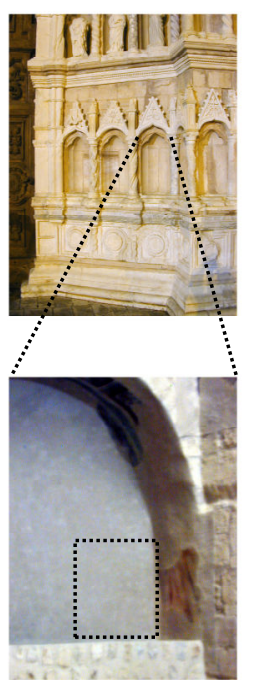

Fig. 6. IRT results for a niche located inside Santa Maria di Collemaggio Church 
Data were collected on two different days and with opposite thermal gradients (one thermogram acquired close to sunrise, the other close to sunset). The result is the same, namely the detection of a buried structure covered with plaster. In this case, the passive approach was sufficient in order to obtain a clear result, instead for the Incoronazione dell'Assunta fresco it was necessary the active approach consisted of one $2 \mathrm{KW}$ halogen lamp.

A long-wave infrared camera (ThermaCAM S65HS from FLIR, 7.5-13 $\mu \mathrm{m}, 320 \times 256$ pixels) was employed and the fresco was inspected from three positions (collecting three sequences) by square pulse thermography, consisting on applying heat for several seconds (480 s) and recording the specimen's cooling down (1500 s).

The positions, were chosen in order to determine if the defects identified by ESPI before the earthquake of 2009 and before the previous restoration, had reappeared again following the earthquake. The comparative results, reported in Figure 2, show that this assumption was correct and then, as the restoration was not accurate.

Figs. $2 c_{2}, c_{1}, c_{3}$ are relative to correlation fringes of three different zones of the fresco where were identified respectively the $A, B, C$ defects (Fig. $2 b_{2}$ ); as stress mode we utilized ambient temperature variations $\left(\Delta T=4^{\circ} \mathrm{C}\right.$ ). The presence of a subsurface cracks (Figs. $2 \mathrm{C}_{2}, \mathrm{C}_{3}$ ), identified by the abrupt interruptions of the interferometric fringes, was revealed using an out-of-plane sensitive configuration of the ESPI system [22]. The profile of the cracks can readily be deduced by the location of fringe discontinuities in the image. Speckle decorrelation (Fig. $2 \mathrm{c}_{4}-$ defect $\mathrm{C}$ ) is simpler and less sensitive than ESPI but able to detect different movements of the surface; in order to prove this, the technique has been applied in conjunction by ESPI technique for the same defect.

Another interferogram (Fig. $2 c_{1}-$ defect B) also revealed the presence of a sub-superficial detachment. A raking light result (Fig. 2a $a_{1}$ ) shows that there is a swelling of the paint just below the crack marked by white arrows in Figure $5 a$.

Very interesting to note the difference in terms of colour between the PCT results reported in Figs. 2a $a_{2}$ (dark spot - EOF2) and $2 b_{1}$ (light spot - EOF7) inherent the defect B, as well as between the phasegram in Fig. 2a $a_{3}$ (light spot) and the PCT-EOF1 (dark spot) inherent the defect D. Both defects are related to sub-superficial detachments, as confirmed by tapping (Fig. $2 b_{2}$ ). Therefore, the integration between ESPI technique and thermographic technique, it is extremely useful: with the first, the fringes's curvature suggests that there is a detachment or a crack beneath the surface, while with the second this is given by the color's difference after the PPT and PCT data processing [51, 52, 53]. If these techniques are used together and combined with the traditional and qualitative coin tap test, the probability of false alarms is substantially reduced.

Another non-destructive testing techniques used in this work was the Ground Penetrating Radar (GPR). The idea to perform GPR measurements on a part of the Church's floor is due to the fact that the masonry facade crosses the longitudinal right masonry according to a right angle (probably indicative of contemporaneity), while the portion of the facade corresponding to the left aisle tends to diverge from the alignment; on the other hand, also the different thickness of the longitudinal walls (105 cm to the right, $95 \mathrm{~cm}$ to the left - Fig. 1a) suggests a non-simultaneous construction of the latter and, in particular, the probable pre-existence of the right side [50].

Therefore, the campaign was carried out to identify underground discontinuities (crypts, tombs, walls) and to correlate them with the presence of ancient and unknown structures [54]. Two series of longitudinal and transverse scans were carried out in order to reach the depth of $6 \mathrm{~m}$ approximately. The scans were performed: 1. back to the central apse, 2. back to the altar near the wooden choir (Fig. 7). Taking into account the excavations results in the area under investigation (Fig. 8a), we can assess more clearly the relative radargrams.

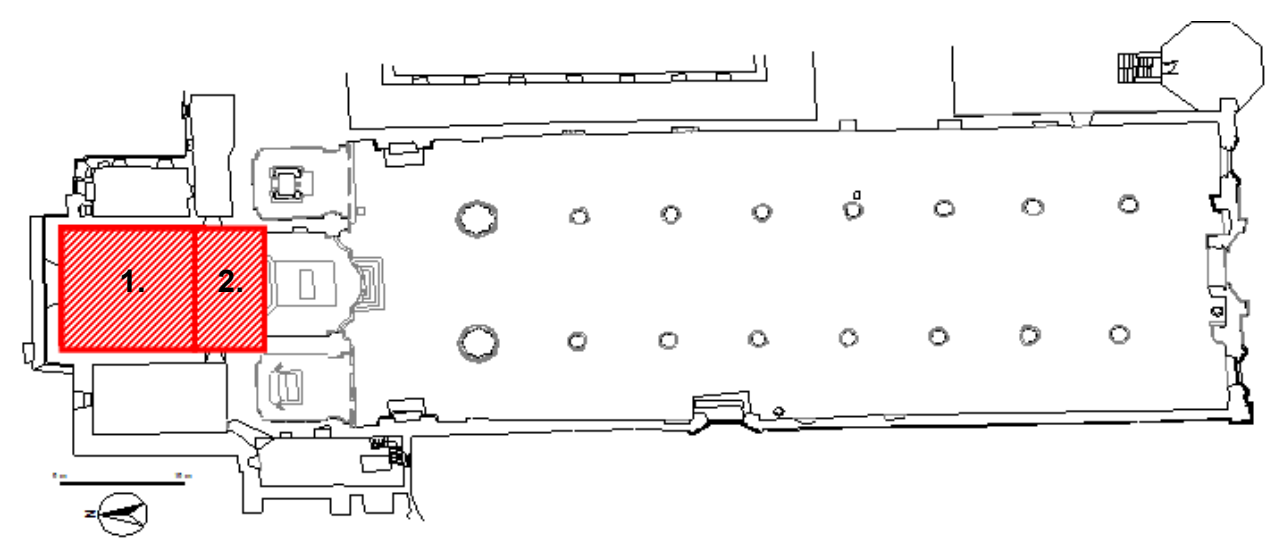

Fig. 7. Floor map of the Santa Maria di Collemaggio Church and identification with red rectangles of the areas where the Ground Penetrating Radar (GPR) technique was carried out

In fact, for both zones is evident that the discontinuities detected are attributable to two types of targets: a) a distributed anomaly with sub-horizontal trend related to the ground-air gap: in this case the target represents the vaults of the cavity and it thickness settles around $1.5 \mathrm{~m}$ below the floor (Fig. 8b); b) an abnormality vertically localized, to be attributed to the presence of a vertical wall (Fig. 8c). In the second grid, there is a deep anomaly distributed, around 2.5 $\mathrm{m}$ below the floor and with a not regular geometry. The second target is also distributed and rather shallow, about $0.70 \mathrm{~m}$ deep, but geometrically well-defined (Fig. 8d). 


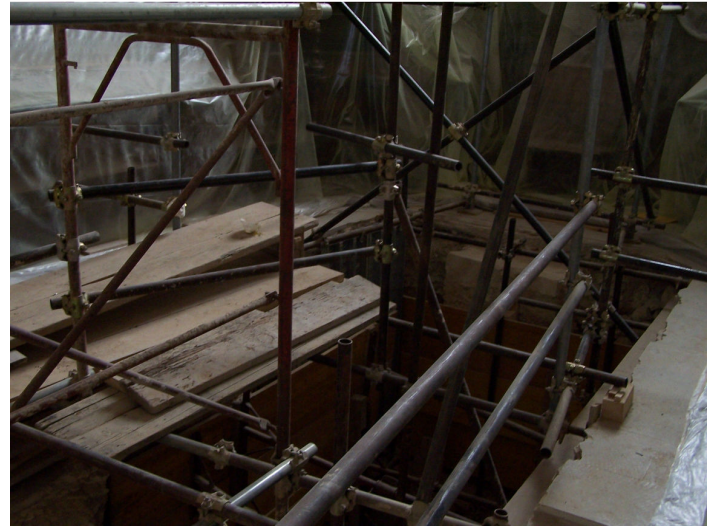

(a)

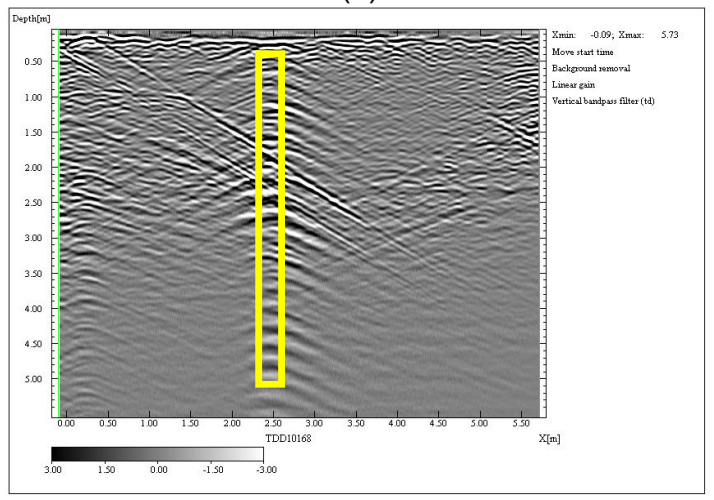

(c)

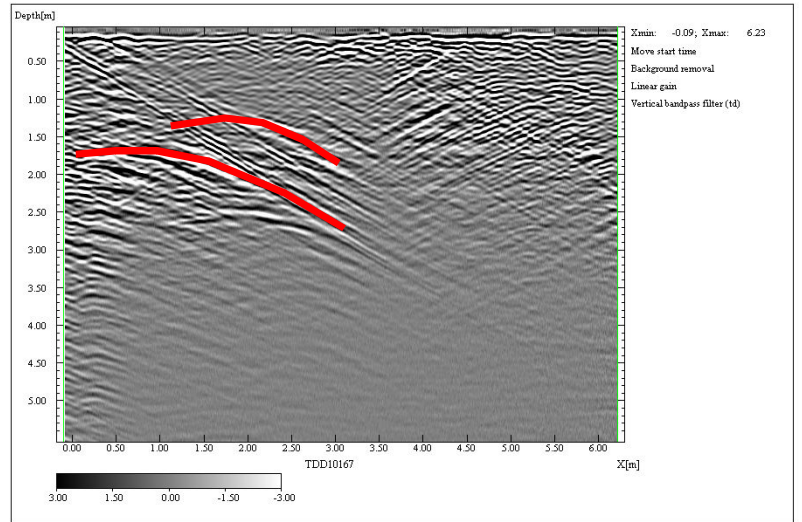

(b)

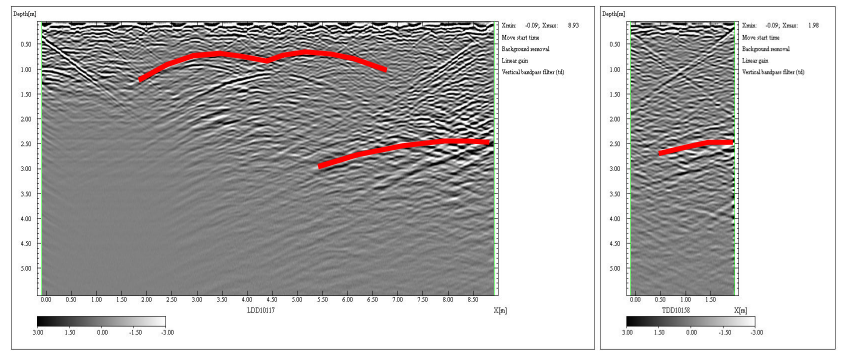

(d)

Fig. 8. (a) Excavation's picture carried out after the GPR surveys (b) Radargram of the first grid: example of distributed anomaly, (c) Radargram of the first grid: example of localized anomaly, (d) Radargram of the second grid: example of distributed anomalies.

Indeed, excavations (Fig. 8a) have uncovered the walls below the Church's floor, which testify the presence of secret underground rooms.

\section{Conclusions}

The integrated and disjoint use of optical, chemical and radar non-destructive testing techniques, has been applied in this work to the main facade, a fresco and a part of the floor of Santa Maria di Collemaggio Church (L'Aquila, Italy).

All the employed NDT techniques have had the same goal of reconstructing the evolutionary history of the Church, which was subjected to restorations over the years, due to several earthquakes.

In particular, passive infrared thermography and ground penetrating radar were applied in order to confirm or deny historical information, whose data are fragmented or lost.

The satisfactory operation of the TV holographic system is illustrated by its application to the analysis of the Incoronazione dell'Assunta fresco situated inside a niche of the Church: the system is very simple to use in situ. The same consideration is possible for square pulsed thermography (SPT) used outside the laboratory.

This work confirms that ESPI or Speckle Decorrelation techniques, and the data processing associated with thermal imaging can be considered for all types of works where one can foresee a degrading reaction to ambient stimuli or mechanical stress (e.g. earthquake). These combined techniques used with the support of raking light and nondestructive chemical techniques, have enabled us to understand not only the shape but also the nature of the subsuperficial defects. On the other hand, the NIR approach was useful to recover both the paint's correction applied due a restoration that the author's pentimenti, inherent the fresco. The latter allowed us to explore the potential of the PCT technique, inasmuch EOF5 and EOF7 have detected three sub-superficial signs, described by palaeographers as gothic. Although their historical origins are certain (taking into account all the collected and described data), their actual meaning remains uncertain, whereas the same signs were also engraved on a stone preserved in the Church.

However, the segmentation result proposed in Fig. 5c provides more insight about whether the signs discovered by PCT are in fact graffiti. Probably, they can be attributed to the author's signature of an earlier fresco painted beneath the present, or they are the initials of the builders' names who worked in the Church's construction.

Although more research is needed at this point in order to fully understand these findings, in any case, "the most beautiful thing we can test is the mystery; it is the source of all true art and all true science" (A. Einstein). 


\section{Acknowledgments}

The following people are warmly thanked for their contribution to this work: Prof. Raimondo Quaresima (University of L'Aquila - DCICM), Prof. Marco Tallini (University of L'Aquila - DISAT), Don Nunzio Spinelli (Rector of the Santa Maria di Collemaggio Church), Mr. Giovanni Pasqualoni (University of L'Aquila - DIMEG).

\section{REFERENCES}

[1] UNESCO, "Our creative diversity: report of the world commission on culture and development". UNESCO Publ., Paris, 1995.

[2] Lowenthal D., "Possessed by the past: the heritage crusade and the spoils of history". Free Press, NY, 1996.

[3] Siddiolo A.M., D’Acquisto L., Maeva A.R., Maev R.G., "Wooden panel paintings investigation: an air-coupled ultrasonic imaging approach", IEEE Transactions on ultrasonics, ferroelectrics, and frequency control, vol. 54, pp. 836-846, 2007.

[4] Grinzato E., Bressan C., Marinetti S., Bison P.G., Bonacina C., "Monitoring of the Scrovegni Chapel by IR thermography: Giotto at infrared", Infrared Physics and Technology, vol. 43, pp. 165-169, 2002.

[5] Grinzato E., Bison P., Marinetti S., Vavilov V., "Nondestructive evaluation of delaminations in fresco plaster using transient infrared thermography", Research in Nondestructive Evaluation, vol. 5, pp. 257-274, 1994.

[6] Carlomagno G.M., Meola C., "Infrared thermography in the restoration of cultural properties", Proceedings of SPIE - The International Society for Optical Engineering, vol. 4360, pp. 203-216, 2001.

[7] Carlomagno G.M., Meola C., "Comparison between thermographic techniques for frescoes NDT", NDT\&E Int., vol. 35, pp. 559-565, 2002.

[8] Ludwig N., Rosina E., "Dynamic IRT for the frescoes assessment, the study case of Danza Macabra in Clusone (Italy)", Proceedings of SPIE - The International Society for Optical Engineering Thermosense XXVII, vol. 5782, pp. 272-279, 2005.

[9] Ibarra-Castanedo C., Sfarra S., Ambrosini D., Paoletti D., Bendada A., Maldague X.P., "Subsurface defect characterization in artworks by quantitative PPT and holographic interferometry", QIRT J., vol. 5, pp. 131-149, 2008.

[10] Valle S., Zanzi L., "Traveltime radar tomography for NDT on masonry and concrete structures". Eur. J. Environ. Eng. Geophys., vol. 2, pp. 229-246, 1998.

[11] Ranalli D., Scozzafava M., Tallini M., "Ground penetrating radar investigations for the restoration of historic buildings: the case study of the Collemaggio Basilica (L'Aquila, Italy)". J. of Cult. Herit., vol. 5, pp. 91-99, 2004.

[12] Sfarra S., Ibarra-Castanedo C., Ambrosini A., Paoletti D., Bendada A., Maldague X., "The use of optical and infrared techniques for the restoration of the frescoes damaged by the earthquake: a case study - the fresco of Giacomo Farelli in the Church of Santa Maria della Croce di Roio (L'Aquila, Italy)", in STREMAH 12, Chianciano Terme (Italy), C.A. Brebbia \& L. Binda ed., 2011.

[13] Sfarra S., Ibarra-Castanedo C., Ambrosini D., Paoletti D., Bendada A., Maldague X., "Integrated approach between pulsed thermography, near-infrared reflectography and sandwich holography for wooden panel paintings advanced monitoring". Russian Journal of Nondestructive Testing, vol. 47, no. 4, pp. 284-293, 2011.

[14] Sfarra S., Theodorakeas P., Ibarra-Castanedo C., Avdelidis N.P., Paoletti A., Paoletti D., Hrissagis K., Bendada A., Maldague X., "Evaluation of defects in panel paintings using infrared, optical and ultrasonic techniques". INSIGHT, vol. 54, no. 1, pp. 21-27, 2012.

[15] Antonacci E., Beolchini G.C., "The dynamic behaviour of the facade of the Basilica S. Maria di Collemaggio". Structural analysis of historical constructions, pp. 469-476, Modena, Lourenço \& Roca Eds., Taylor and Francis Group, London, 2005.

[16] Ambrosini D., Paoletti D., Quaresima R., Galli G., "Frescoes diagnostics: an integrated approach and a case study", Proceedings of 1th EVA Vienna, Wien (Austria), pp. 123-130, 2006.

[17] Pitzalis D., Cassan I., Thomas L., Gianoncelli A., "Non-destructive analyses for modern paintings: the Russian avant-garde case", Proceedings of the $9^{\text {th }}$ International Conference on NDT of Art, Jerusalem (Israel), 2008.

[18] Rastogi P.K., "Digital speckle pattern interferometry and related techniques". Wiley, New York, 2000.

[19] Schirripa Spagnolo G., Ambrosini D., Guattari G., "Electro-optic holography system and digital image processing for in situ analysis of microclimate variations on artworks". J. of Optics, vol. 28, pp. 99-106, 1997.

[20] Gülker G., Hinsch K.D., Holscher C., Kramer A., Neunaber N., "ESPI system for in situ deformation monitoring on buildings". Optical Engineering, vol. 29, pp. 816-820, 1990.

[21] Boone P.M., Markov V.B., "Examination of museum object by means of video holography". Studies in Conservation, vol. 40, pp. 103-109, 1995.

[22] Paoletti D., Schirripa Spagnolo G., "Interferometric methods for artwork diagnostic". Progress in Optics XXXV, pp. 197-255, Elsevier, Amsterdam, 1996.

[23] Lucia A.C., Zanetta P.M., Facchini M., "Electronic speckle pattern interferometry applied to the study and conservation of paintings". Optics and Lasers in Engineering, vol. 26, pp. 221-233, 1997.

[24] Schirripa Spagnolo G., Ambrosini D., Paoletti D., "An NDT electro-optic system for mosaics investigations". J. of Cultural Heritage, vol. 4, pp. 369-376, 2003.

[25] Ambrosini D., Paoletti D., "Holographic and speckle methods for the analysis of panel paintings. Developments since the early 1970s". Reviews in Conservation, vol. 5, pp. 38-48, 2004. 
[26] Dulie-Barton J., Dokos L., Eastop D., Lennard F., Chambers A.R., Sahin M., "Deformation and strain measurement techniques for the inspection of damage in works of art". Reviews in Conservation, vol. 6, pp. 6373, 2005.

[27] Schirripa Spagnolo G., Ambrosini D., Paoletti D., "Optical methods for mosaics diagnosis". Journal of Optics, vol. 29, pp. 394-400, 1998.

[28] Young C., "Measurement of the biaxial properties of nineteenth century canvas primings using speckle pattern interferometry". Optics and Lasers in Engineering, vol. 31, pp. 163-170, 1999.

[29] Gülker G., Hinsch K.D., Kraft A., "Deformation monitoring on ancient terracotta warriors by microscopic TVholography". Optics and Lasers in Engineering, vol. 36, pp. 501-513, 2001.

[30] Hinsch K.D., Gülker G., Helmers H., "Check-up for aging artwork: optical tools to monitor mechanical behaviour". Optics and Lasers in Engineering, vol. 45, pp. 578-588, 2007.

[31] Schirripa Spagnolo G., Ambrosini D., Paoletti D., "Image decorrelation for in situ diagnosis of wooden artifacts". Appl. Opt., vol. 36, pp. 8358-8362, 1997.

[32] Schirripa Spagnolo G., Paoletti D., Ambrosini D., Guattari G., "Electro-optic correlation for in situ diagnosis in mural frescoes". J. of Opt. A Pure and Applied Optics, vol. 6, pp. 557-563, 1997.

[33] Wu H., Siegel M., "Correlation of accelerometer and microphone data in the coin tap test". IEEE Transactions on Instrumentation and Measurement, vol. 49, pp. 493-497, 2000.

[34] Van Asperen de Boer J.R.J., "Infrared reflectography: a method for the examination of paintings". Applied Optics, vol. 7, pp. 1711-1714, 1968.

[35] Bertani D., Cetica M., Poggi P., Puccioni G., Buzzegoli E., Kunzelman D., Cechi S., "A scanning device for infrared reflectography". Studies in Conservation, vol. 35, pp. 113-116, 1990.

[36] Burmester A., Bayerer F., "Towards to improved infrared reflectograms". Studies in Conservation, vol. 38, pp. 145-154, 1993.

[37] Daffara C., Pezzati L., Ambrosini D., Paoletti D., Di Biase R., Mariotti P.I., Frosinini C., "Wide-band IR imaging in the NIR-MIR-FIR regions for in situ analysis of frescoes", Proceedings SPIE 8084, 808406, http://dx.doi.org/10.1117/12.889891, 2011.

[38] Nondestructive Handbook, Infrared and Thermal Testing, vol. 3, Maldague X. technical ed., Moore P.O. ed., $3^{\text {rd }}$ edition, Columbus, Ohio, ASNT Press, p. 718, 2001.

[39] Maldague X.P., "Theory and practice of infrared technology for nondestructive testing", John Wiley \& Sons, N.Y., 2001

[40] Balageas D.L., Krapez J.C., Cielo P., "Pulsed photothermal modeling of layered materials". Journal of Applied Physics, vol. 59, pp. 348-357, 1986.

[41] Martin R.E., Gyekenyesi AlL., Shepard S.M., "Interpreting the results of pulsed thermography data". Materials Evaluation, vol. 61, pp. 611-616, 2003.

[42] Maldague X.P., Marinetti S., "Pulse phase infrared thermography", J. Appl. Phys., vol. 79, pp. 2694-2698, 1996.

[43] Ibarra-Castanedo C., Maldague X., "Pulsed phase thermography reviewed", QIRT J., vol. 1, pp. 47-70, 2004.

[44] Rajic N., "Principal component thermography for flaw contrast enhancement and flaw depth characterization in composite structures", Compos. Struct., vol. 58, pp. 521-528, 2002.

[45] Cather S., "The conservation of wall paintings", The Getty Conservation Institute, Los Angeles, 1991. Available online at http://www.getty.edu/conservation/publications/pdf publications/books.html.

[46] Mora P., Mora L., Philippot P., "Conservation of wall paintings”, Butterworths, London, 1984.

[47] Gonzales R.C., Woods R.E., "Chapter 10: Image Segmentation", Digital Image Processing $3^{\text {rd }}$ Ed., Prentice-Hill, N.Y., 2008.

[48] Bendada A., Sfarra S., Ambrosini D., Paoletti D., Ibarra-Castanedo C., Maldague X.P.V., "Active thermography data processing for the NDT\&E of frescoes", Proceedings of 10th Quantitative InfraRed Thermography conference, paper QIRT2010-015 Québec (Canada), 2010.

[49] Sfarra S., Huke P., Theodorakeas P., Paoletti D., Avdelidis N.P., Ambrosini D., Klattenhoff R., Koui M., "NonDestructive Testing (NDT) methods used for the study of stone frescoes", Proceedings of $6^{\text {th }}$ International Workshop NDT in Progress, Prague (Czech Republic), 2011.

[50] Bartolomucci G., "Santa Maria di Collemaggio, interpretazione critica e problemi di conservazione", Palombi Editore, Roma (Italy), 2004.

[51] Sfarra S., Bendada A., Paoletti A., Paoletti D., Ambrosini D., Ibarra-Castanedo C., Maldague X., "Square Pulse Thermography (SPT) and Digital Speckle Photography (SPT): Nondestructive Techniques (NDT) applied to the defects detection in aerospace materials", Proceedings of $2^{\text {nd }}$ International Symposium on NDT in Aerospace, Hamburg (Germany), 2010.

[52] Sfarra S., Ambrosini D., Paoletti A., Ibarra-Castanedo C., Bendada A., Maldague X., "Quantitative Infrared Thermography (IRT) and Holographic Interferometry (HI): Nondestructive testing for the defects detection in the silicate ceramics industry". Advances in Science and Technology, vol. 68, pp. 102-107, 2010.

[53] Theodorakeas P., Ibarra-Castanedo C., Sfarra S., Avdelidis N.P., Koui M., Maldague X., Paoletti D., Ambrosini D., "NDT inspection of plastered mosaics by means of transient thermography and holographic interferometry". NDT\&E Int., vol. 47, pp. 150-156, 2012.

[54] Sfarra S., "Un esempio di integrazione fra termografia e georadar ai fini della costituzione della carta del rischio del patrimonio artistico abruzzese", Thesis degree, University of L'Aquila, 2006. 